\title{
Gambaran Penurunan Nyeri Pada Penderita Neck Pain Setelah Dilakukan Muscle Energy Technique (MET) : Literature Review
}

\author{
Wildan Sholakhul Huda ${ }^{*}$, Abdurrachman ${ }^{2}$ \\ ${ }_{1,2}$ Prodi Sarjana Fisioterapi Universitas Muhammadiyah Pekajangan Pekalongan,Indonesia \\ *email: wildansh04@gmail.com
}

\begin{abstract}
Neck pain or neck pain is a musculoskeletal complaint such as pain in the neck and stiffness that is often experienced by the community. Around $16.6 \%$ of the adult population in Indonesia complains of neck pain every year. To reduce pain in patients with neck pain, interventions can be given, one of which is Muscle Energy Technique (MET). This study aims to determine the description of pain reduction in patients with neck pain after accepting the Muscle Energy Technique (MET). Writing this article uses a literature review system using PICO. This article was obtained from searching the Microsoft Academic and Scilit online database with predetermined inclusion and exclusion criteria. The measuring instrument used in the literature review is the Visual Analogue Scale (VAS). The results of the literature review analysis of these 5 articles found that the results of pain reduction from the results of the pre-test were 6.13 and post-test were 2.37. So there is a decrease in pain after accepting the Muscle Energy Technique (MET). Muscle Energy Technique (MET) has an effect on reducing pain in Neck Pain cases. It is hoped that this research should be able to increase knowledge about the management of pain reduction in cases of neck pain after accepting the Muscle Energy Technique (MET).
\end{abstract}

Keywords : Neck pain; muscle energy technique (MET); visual analogue scale (VAS).

\begin{abstract}
Abstrak
Neck pain atau nyeri leher merupakan keluhan muskuloskeletal seperti terasa sakit dibagian leher dan kaku yang sering dialami oleh masyarakat. Sekitar $16,6 \%$ setiap tahunnya populasi orang dewasa di Indonesia mengeluhkan rasa nyeri pada leher. Untuk menurunkan nyeri pada penderita Neck pain dapat diberikan intervensi salah satunya adalah Muscle Energy Technique (MET). Penelitian ini bertujuan untuk mengetahui gambaran penurunan nyeri pada penderita Neck pain setelah dilakukan Muscle Energy Technique (MET). Penulisan Artikel ini menggunakan sistem literature review dengan menggunakan PICO. Artikel ini didapatkan dari penelusuran data base online Microsoft Academic dan Scilit dengan kriteria insklusi dan eksklusi yang telah ditentukan. Alat ukur yang digunakan dalam literature review adalah Visual Analogue Scale (VAS). Hasil analisis literature review dari ke 5 artikel ini didapatkan bahwa hasil penurunan nyeri dari hasil pre test 6,13 dan post test 2,37. Jadi ada penurunan nyeri setelah dilakukan Muscle Energy Technique (MET). Muscle Energy Technique (MET) berpengaruh terhadap penurunan nyeri pada kasus Neck pain. Diharapkan Penelitian ini hendaknya dapat meningkatkan pengetahuan terhadap penanganan penurunan nyeri pada kasus Neck pain setelah dilakukan Muscle Energy Technique (MET).
\end{abstract}

Kata Kunci: Neck pain; muscle energy technique (MET); visual analogue scale (VAS).

\section{Pendahuluan}

Neck Pain atau nyeri leher merupakan keluhan muskuloskeletal seperti terasa sakit dibagian leher dan kaku yang sering dialami oleh masyarakat setelah Low Back Pain. Neck pain ialah nyeri yang muncul pada daerah yang dibatasi oleh garis nuchae pada 


\section{Prosiding Seminar Nasional Kesehatan $\mid 2021$ Lembaga Penelitian dan Pengabdian Masyarakat Universitas Muhammadiyah Pekajangan Pekalongan}

bagian atas dan pada bagian bawah oleh garis imajiner transversal melalui ujung processus spinosus thorakal 1, dibagian samping oleh margo lateralis leher (Kudsi, 2015). The Global Burn of Disease Study tahun 2015, menyatakan bahwa prevalensi Neck Pain didunia lebih dari 250 juta orang selama 3 bulan. Di Kanada sebanyak 54\% selama 6 bulan, sedangkan di China sebesar 48,7\% (As-syifa, Hutasoit \& Kareri, 2020). Sekitar $16,6 \%$ setiap tahunnya populasi orang dewasa di Indonesia mengeluhkan rasa nyeri pada leher, bahkan $0,6 \%$ bermula dari timbulnya rasa tidak nyaman menjadi nyeri leher yang berat. Insidensi nyeri leher meningkat seiring dengan bertambahnya usia, dimana lebih sering terjadi pada wanita dibanding pria. (Situmorang, Widjasana \& Wahyuni 2020). ). Penyebab utama Neck Pain kurang dipahami dan biasanya multifaktor, termasuk postur tubuh yang buruk, kecemasan, depresi, ketegangan leher, dan aktivitas olahraga atau pekerjaan (Yadav \& Goyal 2015). Neck pain menyebabkan berkurangnya penggunaan otot yang melibatkan gerakan berulang pada bagian atas karena berpotensi memicu timbulnya rasa nyeri, kelelahan otot dan menurunnya kemampuan fungsional (Kudsi, 2015). Berbagai modalitas fisioterapi dapat digunakan untuk mengurangi nyeri Neck Pain seperti Short Wave Diathermy (SWD), Ultrasound (US), Infra Red(IR), terapi latihan, Massage, dan manual terapi. Pada kasus Neck Pain ini menggunakan modalitas manual terapi salah satunya yaitu berupa Muscle Energy Technique (MET).

Metode ini merupakan manipulasi osteopati jaringan lunak yang menggabungkan secara tepat dimulai, diarahkan dan dikendalikan, dimulai dengan pasien kontraksi isometrik atau isotonik yang dirancang untuk meningkatkan fungsi muskuloskeletal dan mengurangi rasa sakit. Terapi ini dapat digunakan untuk memperpanjang otot yang memendek, memperkuat otot atau sekelompok otot yang melemah secara fisiologis, mengurangi edema lokal dan untuk memobilisasi artikulasi dengan mobilitas terbatas (Toshniwal \& Amarnatha, 2019). Penelitian yang dilakukan oleh Padhke, Bedekar, Shyam \& Sancheti (2016), dari hasil penelitian tersebut menunjukkan bahwa Muscle Energy Technique (MET) efektif dalam meredakan nyeri dan mengurangi kecacatan pada pasien dengan nyeri leher. Penelitian yang dilakukan oleh Ray \& Desai (2021), dari hasil penelitian tersebut menunjukkan bahwa Muscle Energy Technique (MET) lebih efektif untuk mengurangi intensitas nyeri. Dilihat dari latar belakang diatas untuk mengetahui metode Muscle Energy Technique (MET) memiliki pengaruh terhadap penurunan nyeri pada pasien Neck Pain, maka peneliti tertarik untuk melakukan penelitian dengan mengambil judul "Gambaran Penurunan Nyeri Pada Penderita Neck Pain Setelah Dilakukan Muscle Energy Technique (MET) : Literature Review.

\section{Metode}

\section{Pemilihan Artikel}

Pemilihan artikel pada penelitian ini menggunakan PICO, dengan penjelasan sebagai berikut:

P (Population) Pasien dalam penelitian ini adalah pasien yang mengalami Neck Pain.

I (Intervention) Intervensi dalam penelitian ini menggunakan Muscle Energy Technique (MET). 


\section{Prosiding Seminar Nasional Kesehatan Lembaga Penelitian dan Pengabdian Masyarakat Universitas Muhammadiyah Pekajangan Pekalongan}

C (Comparative Intervention) Tidak ada pembanding yang digunakan dalam penelitian.

O (Outcome) Outcome pada penelitian adalah penurunan nyeri.

Jadi pertanyaan dalam penelitian ini adalah "bagaimana Gambaran Penurunan Nyeri Pada Penderita Neck Pain Setelah Dilakukan Muscle Energy Technique (MET) ?".

\section{Seleksi Studi}

Kriteria inklusi meliputi sesuai dengan kata kunci, artikel yang dipublikasikan dalam rentang tahun 2011-2021, menggunakan Bahasa Indonesia maupun Bahasa Inggris, alat ukur menggunakan VAS (Visual Analaog Scale) untuk mengukur tingkat nyeri pada Neck Pain. Kriteria ekslusi meliputi artikel literature review/systematic review.

\section{Hasil dan Pembahasan}

\section{Hasil}

Penelitian ini menggunakan kelima literature artikel dengan tahun artikel penelitian dari tahun 2011-2021 dengan total jumlah responden kelima artikel 89 responden.

1. Karakteristik responden berdasarkan jenis kelamin

Tabel 3.1 Karakteristik Responden Berdasarkan Jenis Kelamin

\begin{tabular}{lccc}
\hline \multicolumn{1}{c}{ Penulis/Tahun/Negara } & Jumlah & \multicolumn{2}{c}{ Jenis kelamin } \\
\cline { 3 - 4 } & & $\mathrm{L}$ & $\mathrm{P}$ \\
\hline $\begin{array}{l}\text { Krupa D. Tangki, Prachi Choksi, } \\
\text { Priyanka Makwana/2018/India }\end{array}$ & 20 & $15(100 \%)$ & $\mathrm{NM}$ \\
\hline $\begin{array}{l}\text { Dhanasekaran Pithcai, } \\
\text { Venkatesan Ramakrishnan, }\end{array}$ & 15 & & 0 \\
Rajashreekar /2020/India & & $\mathrm{NM}$ & $\mathrm{NM}$ \\
\hline $\begin{array}{l}\text { Nipa Patel, Sonali Desai, } \\
\text { Priyanshi Patel /2021/India }\end{array}$ & 15 & $12(42,86 \%)$ & $16(57,14 \%)$ \\
\hline $\begin{array}{l}\text { Apoorva Phadke, Nilima Bedekar, } \\
\text { Ashok Shyam dan Parag }\end{array}$ & 28 & & \\
$\begin{array}{l}\text { Sancheti/2016/India } \\
\text { Harshita Yadav and Manu } \\
\text { goyal./2015/India }\end{array}$ & 11 & $6(54,54 \%)$ & $5(45,45 \%)$ \\
\hline
\end{tabular}

Ket : $\mathrm{L}=$ Laki-laki $\mathrm{P}=$ Perempuan

$\mathrm{NM}=$ Not Mention In Article

Berdasarkan Tabel 3.1 menunjukkan hasil analisis dari 5 artikel penelitian yaitu berjumlah 89 responden. Hasil analisa karakteristik jenis kelamin dari kelima artikel hanya didapatkan 3 artikel yang mencantumkan data karakteristik jenis kelamin dengan jumlah 33 responden laki-laki (54,54\%) dan 21 responden perempuan $(45,45 \%)$. 


\section{Prosiding Seminar Nasional Kesehatan Lembaga Penelitian dan Pengabdian Masyarakat Universitas Muhammadiyah Pekajangan Pekalongan}

2. Karakteristik responden berdasarkan usia

Tabel 3.2 Karakteristik Responden Usia

\begin{tabular}{lccc}
\hline \multicolumn{1}{c}{ Penulis/Tahun/Negara } & Usia & Jumlah & \% \\
\hline $\begin{array}{l}\text { Krupa D. Tangki, Prachi Choksi, } \\
\text { Priyanka Makwana/2018/India }\end{array}$ & $18-45^{\text {th }}$ & 20 & 22,47 \\
\hline $\begin{array}{l}\text { Dhanasekaran Pithcai, Venkatesan } \\
\text { Ramakrishnan, } \\
\text { Rajashreekar/2020/India }\end{array}$ & $18-50^{\text {th }}$ & 15 & 16,85 \\
\hline $\begin{array}{l}\text { Nipa Patel, Sonali Desai, Priyanshi } \\
\text { Patel/2021/India }\end{array}$ & $22-39^{\text {th }}$ & 15 & 16,85 \\
\hline $\begin{array}{l}\text { Apoorva Phadke, Nilima Bedekar, } \\
\text { Ashok Shyam dan Parag } \\
\text { Sancheti/2016/india }\end{array}$ & $18-50^{\text {th }}$ & 28 & 31,46 \\
\hline $\begin{array}{l}\text { Harshita Yadav and Manu } \\
\text { goyal/2015/India }\end{array}$ & $18-45^{\text {th }}$ & 11 & 12,35 \\
\hline \multicolumn{1}{c}{ Total } & & \\
\hline
\end{tabular}

Berdasarkan Tabel 3.2 menunjukan hasil analisis dari 5 artikel yang direview terdapat 89 responden pada kasus Nack Pain dengan rentan usia 18-50 tahun.

3. Hasil pengukuran nyeri pada leher dengan Visual analogue Scale (VAS)

Tabel 3.3 Hasil Analisis Literature Review Penurunan Nyeri Pada Leher Dengan Visual Analogue Scale (VAS)

\begin{tabular}{llccc}
\hline \multicolumn{1}{c}{ Penulis/Tahun/Negara } & \multicolumn{1}{c}{ Dosis } & \multicolumn{3}{c}{ Hasil MET } \\
\cline { 3 - 5 } & & Pre & Post & Range \\
\hline $\begin{array}{l}\text { Krupa D. Tangki, Prachi Choksi, } \\
\text { Priyanka Makwana/2018/India }\end{array}$ & $\begin{array}{l}6 \text { hari selama } \\
\text { 2 minggu }\end{array}$ & 6,64 & 3 & 3,64 \\
\hline $\begin{array}{l}\text { Dhanasekaran Pithcai, } \\
\text { Venkatesan Ramakrishnan, } \\
\text { Rajashreekar/2020/India }\end{array}$ & $\begin{array}{l}5 \text { kali } \\
\text { perminggu } \\
\text { selama } \\
\text { minggu }\end{array}$ & 5,52 & 2,86 & 2,66 \\
\hline $\begin{array}{l}\text { Nipa Patel, Sonali Desai, } \\
\text { Priyanshi Patel/2021/India }\end{array}$ & $\begin{array}{l}\text { 1 hari sekali } \\
\text { selama 1 } \\
\text { minggu }\end{array}$ & 7 & 2,3 & 4,7 \\
\hline $\begin{array}{l}\text { Apoorva Phadke, Nilima } \\
\text { Bedekar, Ashok Shyam dan } \\
\text { Parag Sancheti/2016/india }\end{array}$ & $\begin{array}{l}1 \text { hari sekali } \\
\text { selama 6 hari }\end{array}$ & 5,5 & 1,64 & 3,86 \\
\hline $\begin{array}{l}\text { Harshita Yadav and Manu } \\
\text { goyal/2015/India }\end{array}$ & $\begin{array}{l}5 \text { hari } \\
\text { perminggu } \\
\text { selama 2 } \\
\text { minggu }\end{array}$ & 6,47 & 2,48 & 3,99 \\
\hline Rata-rata & & & & \\
\hline
\end{tabular}

Berdasarkan Tabel 3.3 menunjukan hasil analisis dari 5 artikel didapatkan ratarata nilai pre test sebesar 6,13 dan post test 2,37 dengan rata-rata nilai range sebesar 3,77. 


\section{Prosiding Seminar Nasional Kesehatan $\mid 2021$ Lembaga Penelitian dan Pengabdian Masyarakat Universitas Muhammadiyah Pekajangan Pekalongan}

\section{Pembahasan}

1. Karakteristik responden berdasarkan jenis kelamin

Dilihat dari tabel 3.1 hasil dari 5 artikel penelitian dari 89 responden terdapat $33(61 \%)$ berjenis kelamin laki-laki dan 21 (39\%) berjenis kelamin perempuan dari data tersebut dapat disimpulkan bahwa responden berjenis kelamin laki-laki lebih banyak dibandingkan perempuan disebabkan dari faktor pekerjaan. Pekerjaan yang dilakukan oleh laki-laki cenderung lebih berat dibandingkan perempuan, tentunya lebih mengeluarkan banyak tenaga yang mana menambah beban kerja dari otot sehingga mengakibatkan ketegangan dan kelemahan otot yang dapat beresiko mengalami Neck Pain. Hal ini bertentangan dengan teori dari Yunus (2015) yang menyatakan bahwa berdasarkan beberapa studi, Neck Pain lebih banyak terjadi pada wanita dibandingkan dengan pria. Didukung dari faktor individu jenis kelamin bahwa kapasistas dan ketahanan fisik pekerja berbeda antara perempuan dan lakilaki sehingga dapat diartikan bahwa perempuan lebih cenderung mengalami nyeri pada leher menurut teori dari Cote dkk (2016)

\section{Karakteristik berdasarkan usia}

Hasil literature review pada 5 artikel didapatkan responden dengan karakteristik usia rata-rata 18-50 tahun sebanyak 89 responden dengan rentan usia tersebut. Hasil tersebut sesuai dengan penelitian Apoorva Phadke (2016) yang menggunakan responden dari rentan usia 18-50 tahun. Menurut teori dari Situmorang, Widjasana dan Wahyuni (2020). Mengatakan bahwa seiring dengan bertambahnya usia maka akan mengalami degenerasi sehingga beresiko terkena nyeri leher. Menurut (Robert et al., 2010) Penuaan adalah suatu proses yang mengubah seorang dewasa sehat menjadi seorang yang frail dengan berkurangnya sebagian besar cadangan sistem fisiologis dan meningkatnya kerentanan terhadap berbagai penyakit dan kematian. Pada lanjut usia, individu mengalami banyak perubahan baik secara fisik maupun mental, khususnya kemunduran dalam berbagai fungsi dan kemampuan yang pernah dimilikinya. Penurunan tersebut mengenai berbagai sistem dalam tubuh seperti penurunan daya ingat, kelemahan otot, pendengaran, penglihatan, perasaan dan tampilan fisik yang berubah serta berbagai disfungsi biologis lainnya.

\section{Hasil pengukuran nyeri}

Hasil literature review pada 5 artikel menggunakan alat ukur Visual Analogue Scale didapatkan rata-rata nilai pre test 6,13 dan rata-rata nilai post test 2,37 dengan rata-rata nilai range 3,77 . Yang artinya bahwa terdapat penurunan nyeri pada leher sebelum dan sesudah dilakukan intervensi menggunakan metode Muscle Energy Technique (MET). Hasil penelitian ini sesuai dengan penelitian dari Prerana Toshniwal and T. Kanna Amarnatha (2019) bahwa Muscle Energy Technique (MET) secara efektif dapat menurunkan nyeri leher. Dengan dosis 1 kali sehari selama 1 minggu efektif menghasilkan penurunan nyeri pada leher sesuai dengan penelitian Nipa Patel, Sonali Desai, Priyanshi Patel (2021).

Menurut (Narayan et al 2014) Muscle Energy Technique (MET) merupakan metode manipulasi jaringan lunak yang menggabungkan arahan kepada pasien 


\section{Prosiding Seminar Nasional Kesehatan Lembaga Penelitian dan Pengabdian Masyarakat Universitas Muhammadiyah Pekajangan Pekalongan}

untuk mengontrol gerakan, disertai kontraksi isometrik, yang dirancang untuk meningkatkan fungsi muskuloskeletal serta mengurangi rasa sakit. Menurut (Kudsi, 2015) Neck Pain atau nyeri leher merupakan keluhan muskuloskeletal seperti terasa sakit dibagian leher dan kaku yang sering dialami oleh masyarakat setelah low back pain. Neck Pain ialah nyeri yang muncul pada daerah yang dibatasi oleh garis nuchae pada bagian atas dan pada bagian bawah oleh garis imajiner transversal melalui ujung processus spinosus thorakal 1, dibagian samping oleh margo lateralis leher.

Mekanisme dari Muscle Energy Technique (MET) terhadap penurunan nyeri juga dapat dikaitkan dengan adanya efek hipoalgesik dari Muscle Energy Technique (MET). Karena adanya refleks dari tendon golgi penghambat, yang diaktifkan selama kontraksi isometrik pada relaksasi refleks otot. Aktivasi mekanoreseptor otot dan sendi menghasilkan simpatoeksitasi yang ditimbulkan oleh eferen somatik dan aktivasi lokal yang berperan dalam modulasi nyeri yang menurun (Mahajan, Kataria \& Bansal, 2012).

\section{Simpulan}

Simpulan dari analisis literature review pada kelima artikel penelitian, maka dapat ditarik kesimpulan adanya penurunan nyeri pada kasus Neck Pain setelah dilakukan Muscle Energy Technique (MET).

\section{Referensi}

[1] As-Syifa, R. M., Hutasoit, R. M., \& Kareri, D. G. (2020). Hubungan Antara Sikap Kerja Tehadap Kejadian Neck Pain pada Penjahit di Daerah Kuanino Kota Kupang. 164-170.

[2] Ayubi, M. Z.(2017).Efektivitas Muscle Energy Technique dan Static Stretching Terhadap Keluhan Myofacial Pain Syndrome Otot Upper Trapezius pada Pekerja Batik Laweyan. Skripsi. Universitas Muhammadiyah Surakarta, Surakarta.

[3] Cote, P., Wong, J. J., Sutton, D., Shearer, H. M., Mior, S., Randhawa, K., ...and Salhany, R. (2016). Management of neck pain and associated disorders: A clinical practice guideline from the Ontario Protocol For Traffic Injury Management (OPTIMa) Collaboration European Spine Journal 25(7), 2000-2002.

[4] DhanasekaranPitchai, Venkatesan Ramakrishnan, Rajashreekar.(2020). $A$ Comparative Study Between Maitland Mobilizations Versus Muscle Energy Techniques In Patients With Mechanical Neck Pain. International Journal of Physiotherapy and Research

[5] Huldani.(2013) Neck Pain (Nyeri Leher). Naskah Publikasi. Universitas Lambung Mangkurat, Banjarmasin.

[6] Krupa D. Tank,PrachiChoks, Priyanka Makwana.(2018). To Study The Effect Of Muscle Energy Technique Versus Mulligan Snags On Pain, Range Of Motion And 


\section{Prosiding Seminar Nasional Kesehatan 2021 \\ Lembaga Penelitian dan Pengabdian Masyarakat Universitas Muhammadiyah Pekajangan Pekalongan}

Functional Disability For Individuals With Mechanical Neck Pain". - A Comparative Study. International Journal of Physiotherapy and Research

[7] Kudsi, A. F. (2015). Faktor-faktor yang Mempengaruhi Kejadian Nyeri leher pada Operator Komputer. 258-262.

[8] Narayan, Anupama, Jagga, and Pinay. (2014). Effifacy of Muscle Energy Technique on Function Ability of Shoulder in Adhesive Capsulitis. 72-76.

[9] Patel,N., Desai, S,, \& Patel,P.(2021). Effectiveness of Muscle Energy Technique versus Positional Release Technique on Upper Trapezius Trigger Points in Subjects with Neck Pain - Comparative Study. Radiance Research Academyin International Journal of Current Research and Review.

[10] Phadke, A., Bedekar, N., Shyam, A., \& Sancheti, P. (2016). Effect of muscle energy technique and static stretching on pain and functional disability in patients with mechanical neck pain: $A$ randomized controlled trial. Hong Kong Physiotherapy Journal, 35, 5-11.

[11] Toshniwal, F., and Amarnatha, K. (2019). To Study the Effect of Muscle Energy Technique of Pectoral Muscle on Neck Pain and Cervical Range of Motion in Individuals with Forward Head Posture An Experimental Study. 9, 19-24.

[12] Yadav, H., and Goyal, M. (2015). Efficacy of muscle energy tehcnique and deep neck flexors training in mechanical neck pain: a randomized clinical trial. 52-66.

[13] Yunus, M. A. Hubungan Antara Beban Tas Punggung dengan Non Spesific Neck Pain pada Mahasiswa PSPD UIN Syarif Hidayatullah Jakarta 2015. Skripsi. UIN Syarif Hidayatullah Jakarta. 